\title{
Dental anxiety in relation to torture experiences and symptoms of post-traumatic stress disorder
}

Ann Catrin Høyvik ${ }^{1 *}$, Birgit Lie², Tiril Willumsen ${ }^{1}$

${ }^{1}$ Dept. of Pediatric Dentistry and Behavioral Science, Institute of Clinical Dentistry, Faculty of Dentistry, University of Oslo, Norway

${ }^{2}$ Sorlandet Hospital, Kristiansand, Norway

Running title:

Dental anxiety in torture survivors

*Corresponding author:

Ann Catrin Høyvik, Department of Pediatric Dentistry and Behavioral Science, Faculty of

Dentistry, University of Oslo

P.O. Box 1109 Blindern, N-0317 OSLO, Norway

$(+47) 97077017$

a.c.hoyvik@odont.uio.no 
Høyvik AC, Lie B, Willumsen T. Dental anxiety in relation to torture experiences and symptoms of post-traumatic stress disorder. Eur J Oral Sci

\section{Abstract}

Torture victims often show symptoms of dental anxiety when receiving dental care, but little systematic research is available. The purpose of this study was to explore torture experiences, symptoms of post-traumatic stress disorder (PTSD) and dental anxiety in refugees in Norway and to test the hypothesis that refugees with torture experiences are more prone to dental anxiety. A total of 173 refugees were interviewed shortly after an oral examination. The Modified Dental Anxiety Scale (MDAS) and the Harvard Trauma Questionnaire-PTSS16 (HTQ) were administered verbally through attending interpreters. Among torture victims $(47 \%, n=81)$, the prevalence of torture experiences involving mouth or teeth were $35 \%$ and $23 \%$, respectively. HTQ mean sum-scores were statistically significantly higher in torture victims (34.3 vs. 24.8 ). Torture survivors report more symptoms of PTSD, and dental anxiety is more prevalent in refugees reporting PTSD symptoms. When analysed with logistic regression models, the data showed the odds of high levels of dental anxiety being 6.1 times higher in refugees with torture experiences compared to other refugees and 9.3 times higher in torture victims with PTSD symptoms. Oral health professionals should be aware of these associations when providing dental care to refugees. The hypothesis that tortured refugees are more prone to dental anxiety is supported.

Key words: dental phobia, refugees, ptsd, oral health, vulnerable populations

Ann Catrin Høyvik, Department of Pediatric Dentistry and Behavioral Science, Faculty of Dentistry, University of Oslo, PO Box 1109 Blindern, N-0317 OSLO, Norway

E-mail: a.c.hoyvik@odont.uio.no 
In recent years, Europe has experienced a marked increase in refugees and asylum seekers from countries ravaged by war and riots. Most of these refugees handle the resettlement well, but as a group, they have a high prevalence of mental health problems when compared to both the host populations and to other immigrant groups (1). This may be linked to stressful events before flight, such as torture and other war-related trauma, and stress during the flight itself (2).

According to the United Nations convention against torture, torture comprises intentionally inflicted severe pain or suffering, physical or mental. The inflictor is acting in an official capacity, and has the purpose of obtaining information or confession, punishing, threatening, coercing, intimidating or discriminating (3). The prevalence of torture experience among refugees varies from 5 to 57 percent in different studies, depending on the country of origin and where the studies are conducted, either primary care or specialized health care (4).

In a Danish study, 13 percent of participants who reported having been exposed to torture were referred for a forensic dental examination due to oral health problems, but the authors admit that this group was highly selected (5). Survivors of torture often present with oral pain, missing teeth and need for dental treatment $(6,7)$, and restoring oral conditions may be an important part of the total rehabilitation process, especially when the torture has directly involved the teeth $(7,8)$.

Several aspects of the dental visit resembles the torture situation: The patients may feel tied to the dental chair and are literally underneath health-personnel in white coats administering sharp, metallic instruments with strong resemblance to torture devices. Bright light directed towards the face may reactivate memories of the interrogations and provoke 
loss of control, and victims of water-torture may react strongly to exposure to water in the oral cavity. Thus, it is reasonable to expect victims of torture to experience a certain degree of anxiety in conjunction with dental visits, because this may trigger previous torture experiences $(6,9)$.

Previous research has shown that victims of sexual abuse may be at an increased risk of developing dental anxiety (10). A few studies have also pointed to a correlation between dental anxiety and post-traumatic stress-disorder (PTSD) (11). PTSD and PTSD symptoms correlate positively with torture and other war-related trauma (12), and the main symptoms are increased arousal and reactive symptoms, avoidance behaviour, negative thoughts and feelings, and re-experiencing the trauma through flashbacks and nightmares (13).

Despite the high motivation to have their smile and oral function restored (8), many torture survivors in rehabilitation centres report high levels of dental anxiety $(6,7,9)$. However, to our knowledge the relationship has not been systematically explored.

The aims of the study were i) to determine the prevalence of torture experiences directed against the mouth or teeth in a current refugee population; ii) to test the hypothesis that refugees with torture experience are more prone to dental anxiety than non-tortured individuals in the same refugee population; and iii) to explore the relationship between symptoms of post-traumatic stress disorder (PTSD), torture experience and dental anxiety.

\section{Materials and methods}

To recruit relevant participants, individuals with refugee status in Norway, both resettlement-refugees and asylum seekers granted permanent residency, were invited to 
participate in the study. On arrival in Norway, the Norwegian Directorate of Immigration (UDI) distributes all refugees randomly to reception centres throughout the country, in which they are required to stay in order to receive economical support while awaiting permanent resettlement in municipalities (14). Individuals residing in the eight major reception centres in the eastern part of Norway were invited to participate in the study.

To estimate the sample size, we were interested in the difference in dental anxiety between torture victims in our refugee population and a comparable general population. For comparison, ÅSTR ØM et al. (15) found the Dental Anxiety Scale (DAS) mean-score to be 8.7 (SD 3.7) in a population of 1509 25-yr-old Norwegians. Given a significance level of 5\%, a power of $90 \%$ and a least clinical relevant difference of 2 units, we calculated a need for 37 participants with torture experience. Based on a $20-25 \%$ prevalence of torture experience (16) we aimed to recruit 150-200 refugees.

Data collection took place between December 2013 and June 2015. All adult residents who originated from countries known to practice torture (17) were invited to participate. The exclusion criteria were as follows: (i) age 18 yr or younger, due to the systematic enrollment of this group in the Norwegian public oral health system, and (ii) not fluent in any of the five most common languages among current refugees in Norway (Arabic, Sorani, Tigrinya, Amharic, Somali), or Norwegian or English. The Norwegian Ethics Committee approved the consent form and professional translations were made to all relevant languages. Participants received invitations including the consent form from employees at the reception centres at least one week prior to the data collection. Interpreters were available for illiterate participants. Data were collected on days where the refugees had no planned activities 
outside the reception centres, and of the present invitees only 4 declined to participate. In total, 173 refugees provided written informed consent to take part in the study.

Data collection included an oral examination followed by the verbally administered questionnaires, all performed by the first author who is a trained dentist, and with attending interpreters. All questions were read aloud and registered by the interviewer. The interpreters used written professional translations (18) of the interview guide to ensure equality in the translation process.

Oral examinations were conducted according to the methods described by SINGH et al (6). The dentist used a penlight and headlight, a disposable mouth mirror, disposable gloves and sterile gauze to inspect the mouth. Intra-oral photographs were taken for documentation. Radiographs were not available.

\section{Measures}

The recorded socio-demographic variables were age, gender, educational level (university level /lower), country of birth, preferred language to discuss health issues and the time since arrival in Norway.

The utilization of dental services was measured by asking, "Have you ever visited a dentist?" (yes/no). If yes, "When and where was your last dental visit?". Self-perceived oral health was explored based on two questions: "Are you satisfied with your own teeth?" (yes/no) and "Do you think you have any untreated dental conditions?" (yes/no).

The objective oral treatment need was registered if a participant had either visible tooth decay (defined according to SINGH et al. (6) as $0.5 \mathrm{~mm}$ or more of tooth structure loss at the 
enamel surface and brown coloration of the cavity walls), active periodontitis (mobile teeth combined with visible plaque or calculus), oral pathology or dentures in need of repair.

Torture experience and PTSD symptoms were assessed using the trauma-section of the Harvard Trauma Questionnaire Revised Part 4 (HTQ-R, Table 2) (19), which is an instrument that is already translated to most relevant languages. The cut-off for PTSD as a psychiatric disorder is usually set at 40 , whereas a sum-score of 32 or higher indicates the presence of PTSD symptoms (19).

After answering the HTQ-R, the participants were asked, "Have you been exposed to torture?" (yes/no). If yes, "Have you experienced torture directed towards the (i) face (ii) mouth (iii) or teeth? (yes/no). If no, "Have you been exposed to other systematic abuse?" (yes/no).

Dental anxiety was measured by the Modified Dental Anxiety Scale (MDAS) (20), which consists of five questions: "If you went to the dentist tomorrow, how would you feel?", "If you were sitting in the waiting room, waiting for treatment, how would you feel?", "If you were about to have a tooth drilled, how would you feel?", "If you were about to have your teeth scaled and polished, how would you feel?" and "If you were about to have a local anaesthetic injection in your gum, above an upper back tooth, how would you feel?". The response alternatives ranged from "not anxious" (1) to extremely anxious (5). The cut-off was set at $\geq 15$ for dental anxiety and $\geq 19$ for high levels, described by HUMPHRIS et al. (20) as being very dentally anxious. 


\section{Analysis}

Intra-examiner agreement was tested by examining patients at the Dental Faculty in Oslo at their first and second appointment, before they received dental treatment. For decayed, missing or filled teeth (DMFT) Cohen's Kappa was 0.91 . The examiner had previously been tested for inter-examiner reliability for a study comparing manual and electric toothbrushes (21).

The statistical analyses were performed using SPSS 24.0 (IBM, Chicago, IL, USA). The differences between groups were tested using Pearson's chi-squared tests or Fisher's exact tests for categorical variables and unpaired t-tests, Mann-Whitney U-tests or independent samples Kruskal-Wallis tests for continuous variables. The associations between torture experience and high levels of dental anxiety were studied in logistic regression models with adjustment for gender, age, education and the need for dental treatment. The assumptions for logistic regression models were checked and adequately met. The Hosmer and Lemeshow test indicated no evidence of poor fit ( $p$ values 0.77 and 0.44 ).

\section{Ethics}

To avoid re-traumatizing vulnerable participants, sharp instruments were not used during screening. Following both the dental screening and the interview, there was time for questions and reflections from the participants. The researcher was also available for phone consultations in retrospect. The participants were informed of any pathology found, and when in need of immediate or emergency oral treatment, they were referred to a dentist. Participants with torture experiences and dental treatment need, or other participants with 
high levels of dental anxiety were offered free consultations and dental treatment by specialized teams consisting of dental health personnel and psychologists. The participants were also asked if they needed to speak to a professional health- or social worker about their traumatic experiences not related to dental visits, followed by referral to the public health nurse for follow-up.

The Norwegian Directorate of Immigration (UDI) and the Norwegian Ethics Committee approved the project (2013/1080/REK South-East A).

\section{Results}

The 173 participants originated from 13 different countries although the majority were from Eritrea (62), Syria (42) and Somalia (31). The mean time of residence in Norway was $2.2 \mathrm{yr}$ (median $1.0 \mathrm{yr}$ ). In total, $67 \%$ were men and $47 \%$ having been exposed to torture. Thirtyeight percent of the participants had received dental treatment after arriving in Norway. Table 1 shows the torture experience in relation to gender, age, education, dental treatment experience and subjective and objective oral health measures.

Of the male participants $52 \%$ reported torture experiences, including sexual torture, compared to $37 \%$ of the women. In addition, among the women reporting no torture experience, 31\% reported sexual abuse in situations not defined as torture. Torture prevalence was especially high in refugees from Eritrea (55\%), where several participants expressed unsolicited information regarding imprisonment. In torture survivors, $62 \%(n=50)$ had experienced torture against their face, $35 \%(n=28)$ against the mouth and $23 \%(n=19)$ against the teeth. 
Among participants reporting torture, $53.1 \%$ showed symptoms of PTSD (HTQ-R-sum $\geq 32$ ), compared to $20.7 \%$ of other participants $(P=0.001)$. Mean HTQ-R sum-scores were 34.3 (SD 12.0) and 24.8 (SD 8.0) respectively ( $P=0.001)$. Table 2 lists the 16 PTSD symptoms in the HTQ-R and shows the prevalence of symptoms during the previous week among refugees with and without torture experience.

In refugees presenting with high levels of dental anxiety (MDAS $\geq 19$ ), the HTQ-R mean was 39.9 (SD 14.9) compared to 28.5 in other refugees ( $P=0.001)$. Table 3 shows the MDAS mean score and the levels of dental anxiety in relation to torture experience and PTSD symptoms in all participants. The percentage with dental anxiety was significantly higher in participants with both torture experience and PTSD symptoms when compared to other participants. In refugees with dental treatment-experience after arriving in Norway, the median MDASscore was $11(n=31)$ in torture survivors compared to $7(n=35)$ in other refugees $(P=0.025$, Mann-Whitney U-Test). The boxplot in Fig. 1 displays the MDAS sum-scores in relation to torture experiences (no torture experiences, general torture experiences and torture experiences against teeth) in participants who had dental treatment experiences after their flight compared to those who had not.

Table 4 presents logistic regression models for the association between high levels of dental anxiety (MDAS $\geq 19$ ), torture experience and PTSD symptoms. When adjusting for gender, age, education and self-perceived dental treatment need, the odds of being highly dentally anxious was 6.1 times higher in refugees with torture experience $(P=0.026)$ and 9.3 times higher in torture victims with PTSD symptoms ( $\mathrm{P}=0.005)$. 


\section{Discussion}

This study examined torture experiences, PTSD symptoms and dental anxiety in refugees in Norway and supports the hypothesis that torture victims are more prone to dental anxiety. Although most refugees have suffered from psychological trauma to some extent, PTSD symptoms are significantly more prevalent in refugees with torture experiences. Dental anxiety is more prevalent in refugees suffering from PTSD symptoms, and when controlling for socio-demographic characteristics and self-perceived dental treatment need, refugees with torture experiences are six times more likely to be highly dentally anxious than other refugees.

In the current refugee population, $47 \%$ reported torture. In comparison, a systematic review and meta-analysis of 84 surveys on populations exposed to mass-conflict and displacement, reported experiences of torture in $21 \%$ of the participants (22). The high prevalence in the present study may be explained by the selective inclusion of refugees from countries known to practice torture, since the aim was not to measure torture prevalence in total, but rather to include torture survivors in the study group.

The prevalence of torture against the mouth and teeth was $35 \%$ and $23 \%$, respectively. ARGE et al. (5) found that among torture survivors who were referred to clinical forensic examinations, $13.2 \%$ needed supplementary odontological examinations, which corroborates with another study reporting torture against teeth in $14 \%$ of torture survivors (23). The differences may be due to the heterogeneity of the refugee populations. In addition, in the present study, the memories might be relatively new in the participants' minds since they had just undergone oral screening and were interviewed by a dentist. There is also the question about definition. Torture survivors were asked if they had 
experienced "torture involving their teeth". Some may have defined water torture and oral sexual torture as "involving teeth", whereas others may not. In the study of DANNESKIOLDSAMS $\varnothing \mathrm{E}$ et al. (23), $38 \%$ of the torture victims reported water torture and $19 \%$ reported sexual torture. Our theory was that all types of torture involving the mouth or teeth would increase the survivors' risk of developing dental anxiety.

Participants with torture experiences were consistent with the dentist in their report of dental treatment need, whereas the participants with no torture experiences seemed to under-report their treatment need. This may be seen in connection with the level of education since more participants with education at the university level reported torture experiences. Other studies suggest that immigrants and asylum seekers with an academic degree more often report the need for dental treatment (24). The overall need for oral treatment in the current refugee population was high, with visible carious lesions in $89 \%$ (25). The oral treatment need among torture survivors (84\%) corroborates the results from a US study where $76 \%$ of torture survivors had untreated cavities and $90 \%$ required immediate dental care (6).

Over half of the torture survivors had symptoms of PTSD compared to $21 \%$ of other participants. In a systematic review, STEEL et al. (22) found the prevalence of PTSD in conflict-affected populations to range between $13 \%$ and $25 \%$ and reported that torture was significantly associated with PTSD.

Among torture survivors, the most prevalent PTSD symptoms were avoiding thoughts and feelings or activities that would remind the individual of traumatic and hurtful events, and re-experiencing symptoms. This fits well with the results from a dental anxiety study where $41 \%$ of the subjects with high dental anxiety displayed avoidance behaviour and $43 \%$ had 
symptoms of re-experiencing traumatic events (11). DE JONGH et al. (11) found that severe dental anxiety has many characteristics similar to PTSD and its onset is often triggered by one or more traumatic incidents that are often, but not always, related to dental trauma. Thus, it is reasonable to think that a torture survivor with PTSD symptoms will be more vulnerable to react to triggers during a dental treatment situation and they would be more prone to develop dental anxiety. In a Finnish pilot study (24), 56\% of asylum seekers claimed to be afraid of visiting the dentist and $44 \%$ reported terrifying experiences at dental offices in Finland. Both dental fear and mental stress were more common among asylum seekers than among immigrants in the study group (24). SINGH et al. (6) state that "individuals who have been tortured are often fearful, anxious and panicked when placed in a prone position, and sharp dental objects may trigger recollection of torture".

The overall mean MDAS-score in torture survivors was 9.3 and was not significantly higher than for other refugees. The mean MDAS-score in a representative UK sample was found to be 10.65 (26). The numbers in the present study are quite low in comparison. Several of the interviewees reported that their difficult life situation and the amount of oral pain suppressed any thoughts about being afraid of dental treatment. Because of the massive need for dental treatment in the study group, the high motivation to receive dental treatment may have overruled dental anxiety. Another consideration is that only one-third of the refugees had visited a dentist after experiencing traumatic or hurtful events and that this group expressed significantly more dental anxiety than those who had not seen a dentist. This may indicate that the dental visit triggered psychological reactions and the latter group's view on the matter might change after re-experiencing the dental treatment situation. 
The number of participants with torture experience involving the mouth or teeth was too small to statistically determine whether this group is more dentally anxious than other torture-survivors. However, the results suggest that refugees with dental treatment experience after their flight are more prone to dental anxiety if they have been exposed to torture against their teeth. In a clinical context, this highlights the need for knowledge and adequate psychological consideration from dentists who treat refugees.

When we controlled for gender, age, education and self-perceived dental treatment need, the odds of having high levels of dental anxiety was 6.1 times higher in torture survivors and 9.3 times higher in torture survivors with PTSD symptoms. This fits well with the finding of DE JONGH et al. (11) that being a victim of a violent crime increased the risk for being dentally anxious by 5.6 times. Research on who are most susceptible to post-traumatic distress after torture points to a lack of social support, the number of times detained for political reasons, strong religiousness and female gender (27). In agreement with the present findings, female refugees appear to be at a greater risk for sexual abuse (28), which is a known risk factor for dental anxiety, especially when the abuse involved oral penetration (10).

Some limitations should be acknowledged. The measurements of torture experience, PTSD symptoms and dental anxiety are based on a self-reporting process, which makes it subject to recall bias. Although the question concerning torture experience was linked to the Harvard Trauma Questionnaire, as in most of the surveys reviewed by STEEL et al. (22), there is always the possibility of different personal interpretations of the term. There may also be problems with the cultural specificity in the measures, and all results must be viewed in the light of linguistic challenges. It was not feasible to have all inventories back-translated to all 
languages. However, to ensure equality, all questions were asked orally with attending interpreters, which made it possible to include illiterate participants.

There are multiple pathways to both dental anxiety and PTSD, and many aspects of possible comorbidity are not identified. Many participants mentioned post-migration stressors such as separation from family, social and economic strain and feelings of insecurity but this was not measured systematically or included in our analyses.

The cross-sectional nature of the study is a limitation since it will not allow us to distinguish whether the dental anxiety appeared before or after the torture experiences or whether or not there was a causal relationship between the traumatic experiences and the PTSD symptoms and/or the dental anxiety. Nevertheless, it is highly unlikely that dental anxiety has a causal influence on who are victims of torture or not.

The major strengths were the high participation rate and the representativeness of the study. Interviews and screening were performed at the refugees' residence, and the assessments were made in a neutral context that was temporally and physically distinct from triggers that could elicit anxiety. The sample was representative of current refugees in Norway from countries known to practice torture since refugees are distributed randomly to reception centres throughout the country (14). Some may argue that the heterogeneity of the refugee populations over time affects the generalizability. However, according to Amnesty International (17), every third country practices torture, and the use worldwide seems to be increasing. To our knowledge, this is the first study to compare dental anxiety in torture survivors with non-tortured individuals from the same population. The sample size was sufficient, and the probability of inter-examiner variation was low. Furthermore, undergoing a dental screening before the interviews gave the participants time to gain 
confidence in the researcher, which may have facilitated answering some of the psychologically demanding questions. Studies have also found that traumatic events are more likely to be reported to health care personnel when a professional interpreter is present (29).

In conclusion, a high number of the current refugees reported torture experiences. The prevalence of torture against the mouth and teeth was $35 \%$ and $23 \%$, respectively. In refugee women claiming no torture experience, $31 \%$ reported sexual abuse. To avoid psychological re-traumatization, health personnel, including dentists, must consider this when providing health care to refugees.

The hypothesis that tortured refugees are more prone to dental anxiety is supported. Although dental anxiety may not be a major issue for the refugee population as a whole, some traumatized individuals are extremely anxious. Torture survivors report significantly more symptoms of PTSD, and dental anxiety is more prevalent in refugees suffering from PTSD symptoms. Oral health professionals should be aware of this and be attentive when they meet refugee patients with evident dental anxiety. In addition, the following questions arise. Will this patient conceal other psychological issues that have not been addressed? Does this patient receive proper mental and physical health care? The patient may have PTSD and/or be a torture victim. Is there a need for a further referral? 


\section{Acknowledgements and funding}

Beata Petrovski at the Dental Faculty, University of Oslo contributed with valuable statistical advice. The authors would also like to thank the Norwegian Directorate of Immigration, particularly the personnel at the reception centers Bjørnebekk, Bærum, Dikemark, Drammen, Hobøl, Moss, Skedsmo and Tønsberg. This research received no specific grant from any funding agency, but interpretation services were supported by the Norwegian Directory of Health.

\section{Conflict of interest statement}

The authors declare that they have no conflict of interest. 


\section{References}

1. EKBLAD S, KAStRUP MC. Current research in transcultural psychiatry in the Nordic countries. Transcult Psychiatry 2013; 50: 841-857

2. LIE B. The triple burden of trauma, uprooting and settlement. 2003. Doctoral dissertation, University of Oslo, Norway, 2003.

3. Convention against torture and other cruel, inhuman or degrading treatment or punishment. New York: United Nations, 1984.

4. Rabin M, Willard C. Torture and refugees. In: Annamalal A, ed. Refugee health care: An essential medical guide. New York: Springer, 2014; 181-92.

5. Arge So, hansen SH, Lynnerup N. Forensic odontological examinations of alleged torture victims at the University of Copenhagen 1997-2011. Torture 2014; 24: 1724

6. Singh HK, Scott Te, Henshaw MM, Cote Se, Grodin MA, Piwowarczyk LA. Oral Health Status of Refugee Torture Survivors Seeking Care in the United States. Am J Public Health 2008; 98: 2181-2182

7. BØJHOLM S., JøRRING L., BAKKE M. Torturoverlevere - generelle og odontologiske aspekter. Tandlægebladet 1995; 99: 910-912

8. JeRLANg P. Odontological Treatment of Torture Victims. Torture 1992; 1 (Suppl): $38 S-40 S$

9. Jerlang B, Orloff J, Jerlang P. Torturoverlevere - psykologiske og odontologiske aspekter. Tandlægebladet 1995; 99: 906-909

10. Willumsen T. Dental fear in sexually abused women. Eur J Oral Sci 2001; 109: 291296 
11. De Jongh A, Fransen J, Oosterlink-Wubbe F, Aartman I. Psychological trauma exposure and trauma symptoms among individuals with high and low levels of dental anxiety. Eur J Oral Sci 2006; 114: 286-292

12. IBRAhim H, Hassan CQ. Post-traumatic Stress Disorder Symptoms Resulting from Torture and Other Traumatic Events among Syrian Kurdish Refugees in Kurdistan Region, Iraq. Front Psychol 2017; 8: 241.

13. Diagnostic and statistical manual of mental disorders. $5^{\text {th }}$ edition. Arlington, VA: American Psychiatric Association (APA), 2013.

14. Fordeling av asylsøkere fra transittmottak til ordinære mottak, rundskriv RS 2011 044. (Distribution of asylum seekers from transit to ordinary reception centers). Oslo: Norwegian Directorate of Immigration (UDI), 2011

15. Astrøm AN, Skaret E, Haugejorden O. Dental anxiety and dental attendance among 25-year-olds in Norway: time trends from 1997-2007. BMC Oral Health 2011; 11: 10

16. LIE B. A 3-year follow-up study of psychosocial functioning and general symptoms in settled refugees. Acta Psychiatr Scand. 2002; 106: 415-425

17. Amnesty International Report 2017/18. London, UK: Amnesty International 2018

18. Salita Interpretation- and translation services. Oslo, Norway.

19. Shoeb M, Weinstein H, Mollica R. The Harvard Trauma Questionnaire: Adapting a cross cultural instrument for measuring torture, trauma and posttraumatic stress disorder in Iraqi refugees. Int J Psychiatry 2007; 53: 447-63

20. HUMPHRIS GM, MORRISON T, LINDSAY SJ. The modified dental anxiety scale: validation and United Kingdom norms. Community Dent Health 1995; 12: 143-50 
21. AASS AM, GJERMO P. Comparison of oral hygiene efficacy of one manual and two electric toothbrushes. Acta Odontol Scand 2000, 58: 166-170

22. Steel Z, Chey T, Silove D, Marnane C, Bryant RA, van Ommeren M. Association of torture and other potentially traumatic events with mental health outcomes among populations exposed to mass conflict and displacement. A systematic review and meta-analysis. JAMA 2009; 302: 537-549

23. Danneskiold-Sams $\varnothing$ E B, Bartels EM, Genefke I. Treatment of torture victims - a longitudinal clinical study. Torture 2007; 1: 11-17

24. Mattila A, Ghaderi P, Tervonen L, Niskanen L, Pesonen P, Anttonen V, Laitala Ml. Selfreported oral health and use of dental services among asylum seekers and immigrants in Finland - a pilot study. Eur J Public Health 2016; 26: 1006-1010

25. HøYVIK AC, LIE B, GrJibovski AM, WiLlumSEN T. Oral health challenges in refugees from the Middle East and Africa: a comparative study. J Immigr Minor Health 2018; https://doi.org/10.1007/s10903-018-0781-y

26. Humphris G, Crawford JR, Hill K, Gilbert A, Freeman R. UK population norms for the modified dental anxiety scale with percentile calculator: adult dental health survey 2009 results. BMC Oral Health 2013; 13: 29

27. Halvorsen J $\varnothing$, Kagee A. Predictors of psychological sequelae of torture among South African former political prisoners. J Interpers Violence 2010; 25: 989-1005

28. Sanders J, Schuman MW, Marbella AM. The epidemiology of torture: a case series of 58 survivors of torture. Forensic Sci Int. 2009; 189: e1-e7

29. Eytan A, Bischoff A, Rrustemi I, Durieux S, Loutan L, Gilbert M, Bovier PA. Screening of mental disorders in asylum-seekers from Kosovo. Aust NZJ Psychiatry 2002; 36: 499-503 


\section{Figure 1}

Boxplot of MDAS sum-scores vs. torture experiences in refugees with and without dental treatment experience after their flight. Statistical differences are tested with Kruskal-Wallis test for independent samples.

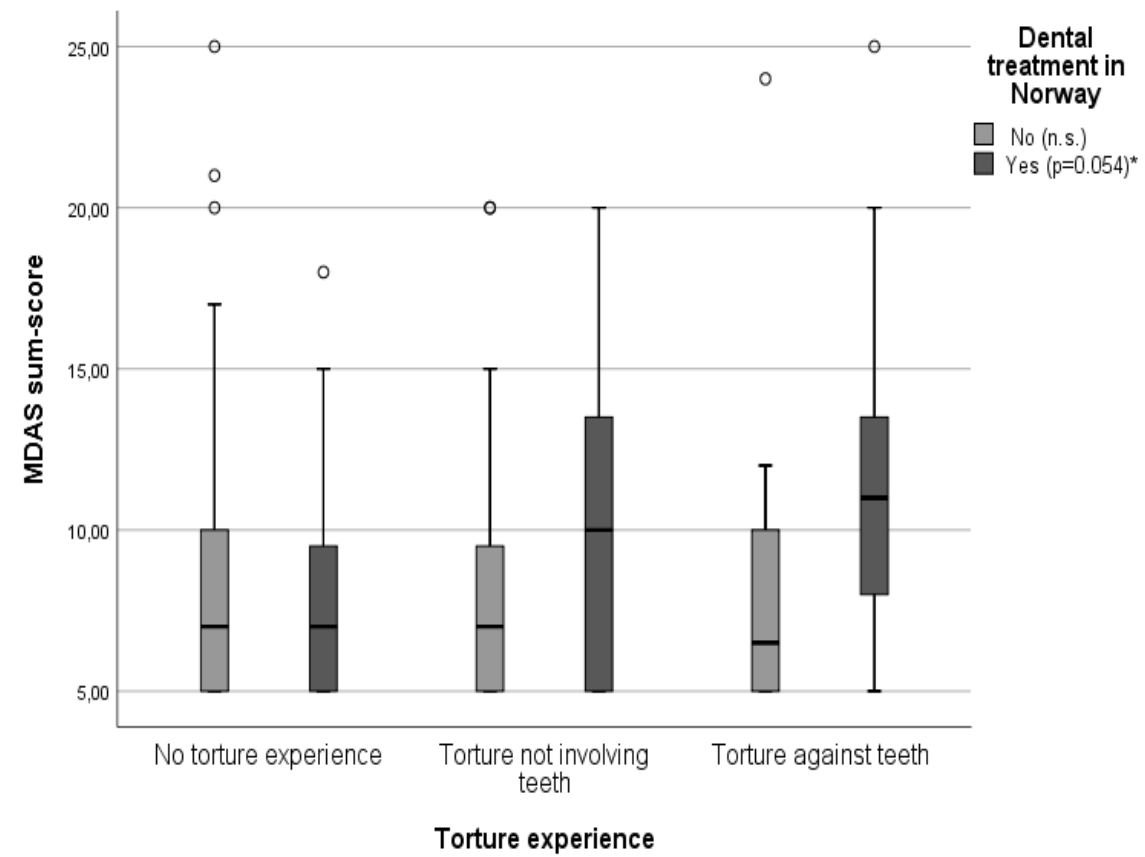

*Independent samples Kruskal-Wallis test 
Table 1 - Torture experience in relation to demographics, dental treatment experience and oral health.

\begin{tabular}{|c|c|c|c|c|}
\hline & & $\begin{array}{c}\text { Torture experience } \\
\qquad \mathbf{N}=81\end{array}$ & $\begin{array}{c}\text { No torture experience } \\
\mathrm{N}=92\end{array}$ & $\mathbf{P}^{*}$ \\
\hline \multirow[t]{2}{*}{ Gender } & Female & $21(25.9 \%)$ & $36(39.1 \%)$ & 0.065 \\
\hline & Male & $60(74.1 \%)$ & $56(60.9 \%)$ & \\
\hline \multirow[t]{2}{*}{ Age } & $19-30 \mathrm{yr}$ & $35(43.2 \%)$ & $52(56.5 \%)$ & 0.081 \\
\hline & $>30 \mathrm{yr}$ & $46(56.2 \%)$ & $40(43.5 \%)$ & \\
\hline \multicolumn{2}{|c|}{ Education at the university level } & $23(28.4 \%)$ & $14(15.2 \%)$ & 0.035 \\
\hline \multicolumn{2}{|c|}{ Dental treatment experience } & $56(69.1 \%)$ & $66(71.7 \%)$ & 0.708 \\
\hline \multicolumn{2}{|c|}{ Satisfied with their teeth } & $32(39.5 \%)$ & 49 (53.3\%) & 0.070 \\
\hline \multicolumn{2}{|c|}{ Subjective oral treatment-need } & $70(86.4 \%)$ & $64(69.6 \%)$ & 0.008 \\
\hline \multicolumn{2}{|c|}{ Dentist-determined treatment-need } & $68(84.4 \%)$ & $73(79.3 \%)$ & 0.437 \\
\hline
\end{tabular}

*Chi-square test 
Table 2 - Percentage of participants reporting PTSD symptoms during the previous week

\begin{tabular}{|c|c|c|c|}
\hline PTSD-symptom & $\begin{array}{c}\text { Torture } \\
\text { experience } \\
(n=81)\end{array}$ & $\begin{array}{l}\text { No torture } \\
\text { experience } \\
(n=92)\end{array}$ & p* \\
\hline $\begin{array}{l}\text { Recurrent thoughts or memories of the most hurtful } \\
\text { or terrifying events }\end{array}$ & 46.9 & 18.5 & 0.001 \\
\hline Feeling as though the event is happening again & 34.6 & 9.8 & 0.001 \\
\hline Recurrent nightmares & 29.6 & 8.7 & 0.001 \\
\hline Feeling detached or withdrawn from people & 22.2 & 12.0 & 0.071 \\
\hline Unable to feel emotions & 17.3 & 3.3 & 0.002 \\
\hline Feeling jumpy, easily startled & 32.1 & 19.6 & 0.059 \\
\hline Difficulty concentrating & 27.2 & 13.0 & 0.020 \\
\hline Trouble sleeping & 33.3 & 8.7 & 0.001 \\
\hline Feeling on guard & 30.9 & 8.7 & 0.001 \\
\hline Feeling irritable or having outbursts of anger & 28.4 & 9.8 & 0.002 \\
\hline $\begin{array}{l}\text { Avoiding activities that remind you of the traumatic } \\
\text { or hurtful event }\end{array}$ & 59.3 & 30.4 & 0.001 \\
\hline $\begin{array}{l}\text { Inability to remember parts of the most hurtful or } \\
\text { traumatic events }\end{array}$ & 21.0 & 14.1 & 0.235 \\
\hline Less interest in daily activities & 14.8 & 5.4 & 0.039 \\
\hline Feeling as if you don't have a future & 16.0 & 1.1 & 0.001 \\
\hline $\begin{array}{l}\text { Avoiding thoughts or feelings associated with the } \\
\text { traumatic or hurtful events }\end{array}$ & 69.1 & 34.8 & 0.001 \\
\hline $\begin{array}{l}\text { Sudden emotional or physical reaction when } \\
\text { reminded of the most hurtful or traumatic event }\end{array}$ & 48.1 & 15.2 & 0.001 \\
\hline
\end{tabular}


Table 3 - Comparison of the MDAS mean sum-score, the percentage with dental anxiety (MDAS $\geq 15$ ) and the percentage with high levels of dental anxiety (MDAS $\geq 19$ ) in refugees with or without torture experience, PTSD symptoms and the combination of torture experience and PTSD symptoms.

\begin{tabular}{|c|c|c|c|c|c|c|}
\hline & MDAS mean & $\mathbf{p}$ & MDAS $\geq 15$ & $\mathbf{p}$ & MDAS $\geq 19$ & $\mathbf{p}$ \\
\hline Torture experience $(n=81)$ & 9.3 (SD 5.0) & $0.118 *$ & $13.6 \%$ & $0.586^{1}$ & $9.9 \%$ & $0.075^{1}$ \\
\hline Other participants ( $n=92$ ) & 8.2 (SD 4.2) & & $10.9 \%$ & & $3.3 \%$ & \\
\hline PTSD symptoms ( $n=62)$ & 10.6 (SD 5.3) & $0.001 *$ & $24.2 \%$ & $0.001^{1}$ & $12.9 \%$ & $0.018^{2}$ \\
\hline Other participants ( $n=111)$ & 7.7 (SD 3.8) & & $5.4 \%$ & & $2.7 \%$ & \\
\hline $\begin{array}{l}\text { PTSD symptoms and } \\
\text { torture experience }(n=43)\end{array}$ & 10.9 (SD 5.6) & $0.001 *$ & $23.3 \%$ & $0.010^{1}$ & $16.3 \%$ & $0.006^{2}$ \\
\hline Other participants ( $n=130)$ & 8.0 (SD 4.0) & & $8.5 \%$ & & $3.1 \%$ & \\
\hline
\end{tabular}

*Unpaired t-test ${ }^{1}$ Pearson's Chi square test ${ }^{2}$ Fisher's exact test 
Table 4 - Odds ratios (ORs) for high levels of dental anxiety (MDAS $\geq 19$ ) in participants with torture experience and participants with both torture experience and PTSD symptoms; calculated using logistic regression analysis.

\begin{tabular}{|c|c|c|c|c|c|c|c|}
\hline \multirow[t]{2}{*}{ Variable } & & \multicolumn{3}{|c|}{ Unadjusted effects } & \multicolumn{3}{|c|}{ Adjusted effects } \\
\hline & & OR & $95 \% \mathrm{Cl}$ & $\mathbf{p}$ & OR & $95 \% \mathrm{Cl}$ & $\mathbf{p}$ \\
\hline \multirow[t]{2}{*}{ Torture experience } & No (ref.) & 1 & & & 1 & & \\
\hline & Yes & 3.25 & $0.83-12.70$ & 0.090 & 6.12 & $1.25-30.29$ & 0.026 \\
\hline \multirow[t]{2}{*}{ Gender } & Male (ref.) & 1 & & & 1 & & \\
\hline & Female & 3.92 & $1.10-14.00$ & 0.035 & 9.50 & $2.01-44.97$ & 0.005 \\
\hline \multirow[t]{2}{*}{ Age } & $19-30$ (ref.) & 1 & & & 1 & & \\
\hline & $>30$ & 0.83 & $0.24-2.84$ & 0.771 & 0.80 & $0.19-3.35$ & 0.761 \\
\hline \multirow[t]{2}{*}{ University level education } & No (ref.) & 1 & & & 1 & & \\
\hline & Yes & 3.39 & $0.97-11.80$ & 0.056 & 4.20 & $0.98-18.10$ & 0.054 \\
\hline \multirow[t]{2}{*}{ Dental treatment need } & No (ref.) & 1 & & & 1 & & \\
\hline & Yes & 0.48 & $0.13-1.74$ & 0.266 & 0.23 & $0.05-1.16$ & 0.075 \\
\hline \multirow{2}{*}{$\begin{array}{l}\text { Torture experience } \\
\text { and PTSD symptoms }\end{array}$} & No (ref.) & 1 & & & 1 & & \\
\hline & Yes & 6.13 & $1.70-22-10$ & 0.006 & 9.26 & $1.93-44.45$ & 0.005 \\
\hline \multirow[t]{2}{*}{ Gender } & Male (ref.) & 1 & & & 1 & & \\
\hline & Female & 3.92 & $1.10-14.00$ & 0.035 & 7.09 & $1.48-33.92$ & 0.014 \\
\hline \multirow[t]{2}{*}{ Age } & $19-30$ (ref.) & 1 & & & 1 & & \\
\hline & $>30$ & 0.83 & $0.24-2.84$ & 0.771 & 0.98 & $0.90-1.04$ & 0.365 \\
\hline \multirow[t]{2}{*}{ University level education } & No (ref.) & 1 & & & 1 & & \\
\hline & Yes & 3.39 & $0.97-11.80$ & 0.056 & 4.96 & $1.05-23.54$ & 0.044 \\
\hline \multirow[t]{2}{*}{ Dental treatment need } & No (ref.) & 1 & & & 1 & & \\
\hline & Yes & 0.48 & $0.13-1.74$ & 0.266 & 0.20 & 0.04-1.02 & 0.053 \\
\hline
\end{tabular}

